\title{
Canadian regulations and legal ramifications for hepatic encephalopathy: a descriptive analysis
}

\author{
Henry H. Nguyen MD, Mark G. Swain MD MSc, Philip Wong MD MSc, Stephen E. Congly MD MSc
}

Abstract

Background: Hepatic encephalopathy, a form of brain dysfunction seen in the setting of liver insufficiency, negatively affects driving performance and so is both a patient and public safety issue. We aimed to review the motor vehicle codes in each Canadian province and territory relating to the reporting of patients with hepatic encephalopathy and to search a Canadian legal database for cases of motor vehicle collisions involving patients with hepatic encephalopathy.

Methods: In this descriptive analysis, the transportation agencies of each Canadian province and territory were contacted via telephone and/or email between April and August 2017. Requirements of physicians to report medical conditions (including liver disease and hepatic encephalopathy) affecting a patient's fitness to drive were assessed. WestlawNext Canada was searched for any Canadian cases on hepatic encephalopathy and driving-related lawsuits from inception to Dec. 31, 2017.

Results: Reporting of medically unfit drivers is a requirement in all Canadian provinces and territories except Alberta, Quebec and Nova Scotia. Hepatic encephalopathy, cirrhosis and advanced liver disease were not specifically identified as reportable medical conditions in any province or territory. Our search did not identify any lawsuits involving a motor vehicle collision in Canada that were made either against physicians caring for patients with hepatic encephalopathy or against such patients themselves.

Interpretation: Although hepatic encephalopathy has a substantial impact on driving performance, it is not specifically identified as a reportable medical condition in Canada. Increasing awareness of the potential impact of hepatic encephalopathy on safe driving for health care providers and the public is critical.

hronic liver disease is a common medical condition, with end-stage liver cirrhosis having a prevalence of $0.27 \%$ in the general population. ${ }^{1}$ The prevalence of cirrhosis is expected to increase in the future, given the impact of hepatitis $\mathrm{C}^{2}$ and the rapid increase in nonalcoholic fatty liver disease among the Canadian population, affecting up to $30 \%$ of Canadians. ${ }^{3}$ Hepatic encephalopathy is a wellrecognized complication of cirrhosis characterized by brain dysfunction, with up to $50 \%$ of patients with cirrhosis developing this complication. ${ }^{4}$ Symptoms of hepatic encephalopathy can range from subclinical aberrations in neurologic and psychological domains to deep coma and death. ${ }^{5}$ Overt hepatic encephalopathy is readily diagnosed in the clinical setting; however, up to $55 \%$ of patients with cirrhosis can have covert or minimal hepatic encephalopathy that is detected only with neuropsychometric testing. ${ }^{6,7}$

The complex task of driving involves the effective integration of sensory input, cognition and motor functions. ${ }^{8}$ Patients with minimal hepatic encephalopathy have impairments in attention, psychomotor speed and visuospatial perception as well as delayed response, ${ }^{9,10}$ which all may impair their ability to safely operate a motor vehicle. Impairment in these domains, including cognitive deficits, prolonged reaction time, poor handling of motor vehicles and reduced cautiousness, have been associated with substantially reduced driving performance on road testing in patients with hepatic encephalopathy. ${ }^{11,12}$ Studies using neuropsychometric testing have found that up to $60 \%$ of patients with minimal hepatic encephalopathy are probably unfit to drive. ${ }^{13}$ Self-reported data from patients with cirrhosis are congruent with these results, showing that patients with a history of minimal hepatic encephalopathy have substantially more motor vehicle collisions than those without. ${ }^{14}$ Given this finding and a recent report by Transport Canada's National Collision Database that approximately 116000 motor vehicle crashes in Canada

Competing interests: Mark Swain has served as a speaker and/or advisory board member and/or has received research support from Allergan, Genfit, Bristol-Myers Squibb, Gilead Sciences, CymaBay Therapeutics, Abbott, Intercept Pharmaceuticals, Genkyotex, Novartis, GlaxoSmithKline, AbbVie and Merck outside the submitted work. He has served as a data and safety monitoring committee member in clinical trials for Gilead Sciences and GRI Bio outside the submitted work. Stephen Congly reports receiving grants and personal fees from Allergan and grants from Gilead Sciences, Genfit, Boehringer Ingelheim and Bristol-Myers Squibb outside the submitted work. No other competing interests were declared.

This article has been peer reviewed.

Correspondence to: Stephen Congly, secongly@ucalgary.ca

CMAJ Open 2018. DOI:10.9778/cmajo.20180024 
resulted in personal injury in $2015,{ }^{15}$ it is important that patients with chronic liver disease/liver cirrhosis be assessed for evidence of hepatic encephalopathy and that fitness to drive be addressed in the setting in which hepatic encephalopathy is diagnosed. In the United States, a recent study showed that only $12 \%$ of states have mandatory reporting laws. ${ }^{16}$ Similarly, the General Medical Council in the United Kingdom recently released guidance on reporting of patients who are unfit to drive, which outlined a physician's professional duty to report medically unfit drivers; ${ }^{17}$ however, it was not explicitly stated that this was legally mandatory. ${ }^{18}$ In Canada medical reporting requirements for unfit drivers vary between provinces, and currently there are no clear standard guidelines for either the assessment of fitness to drive or the reporting of patients with hepatic encephalopathy either in the current edition of the Canadian Medical Association driving guidelines ${ }^{19}$ or the Canadian Council of Motor Transport Administrators standards. ${ }^{20}$ As such, patients and medical providers could potentially be liable if a motor vehicle collision occurred because of hepatic encephalopathy. Although a US study did not find evidence of litigation in this area, ${ }^{16}$ at present there are no Canadian data about potential legal implications for providers or patients. The purpose of this study was to investigate and provide an overview of the requirement of each Canadian province and territory for physician reporting of patients who are medically unfit to drive and to assess whether this requirement explicitly includes patients with any degree of hepatic encephalopathy. Furthermore, we wished to determine whether there have been any Canadian legal decisions against physicians caring for patients with hepatic encephalopathy who failed to report unsafe drivers/patients with hepatic encephalopathy in the setting of motor vehicle collisions.

\section{Methods}

\section{Data sources}

To assess the requirements for reporting of impaired drivers in the setting of a general medical condition, we contacted each provincial and territorial motor vehicle department directly by telephone and/or email between April and August 2017 (H.H.N.) and reviewed the available motor vehicle codes of each province and territory (H.H.N. and S.E.C.). A direct response from a province's or territory's motor vehicle department was treated as the primary information source. For provinces/territories for which a response could not be obtained, the online motor vehicle code was considered the primary source. Variables to be collected were determined before the initiation of the study. Data collection was carried out in a similar manner for all provinces and territories. Data collected from the provinces and territories assessed the requirement for the following: (a) mandatory reporting by physicians of known medical conditions, (b) mandatory reporting of known hepatic encephalopathy (overt or covert), (c) mandatory reporting of patients with chronic liver disease, (d) legal immunity for physicians who report these individuals, (e) use of health questionnaires before issuing a driving licence and (f) involvement of a medical advisory board for determining driving fitness.
WestlawNext Canada, the most comprehensive database of reported Canadian judicial decisions, regulations and statutes as well as Canadian law journals and reviews, was searched for cases involving lawsuits filed against physicians and/or patients with chronic liver disease and/or hepatic encephalopathy who were involved in motor vehicle collisions. This database includes digests of virtually every case reported in Canada since $1803 .{ }^{21}$ A broad search strategy was created with the help of a legal librarian to reduce the likelihood that any relevant cases would be missed (Appendix 1, available at www.cmajopen.ca/content/6/4/E575/suppl/DC1). Abstracts of decisions and articles were reviewed, and documents associated with any abstract that could potentially reference civil or criminal charges against physicians caring for patients with hepatic encephalopathy or the patient themselves were subsequently retrieved for full-text review.

\section{Data analysis}

Descriptive analysis was performed for the review of provincial and territorial reporting requirements and for the legal database review.

\section{Ethics approval}

Ethics approval was not required as the data used in this study came either from published literature or from government agencies.

\section{Results}

\section{Provincial and territorial reporting requirements}

A summary of provincial and territorial reporting requirements is provided in Table 1 . In most provinces and territories $(n=10)$, it was mandatory for physicians to report medical conditions impairing a patient's ability to safely operate a motor vehicle. In the remaining provinces $(n=3)$, specifically Alberta, Quebec and Nova Scotia, mandatory reporting was not required. No response was obtained from Nunavut, despite repeated contact attempts via telephone and email. In all provinces and territories $(n=13)$, reporting physicians were granted legal immunity. In regions where reporting was mandatory, terms including general debility, cognitive impairment and metabolic diseases were highlighted as reportable medical conditions. Hepatic encephalopathy, liver cirrhosis or advanced liver disease, however, were not specifically identified as reportable medical conditions.

In most provinces and territories $(n=11)$, a medical questionnaire had to be completed or specific questions had to be answered before a licence was issued. Most of the questionnaires were for screening purposes, and as such they did not assess for specific medical conditions including chronic liver disease and/or hepatic encephalopathy. However, if an individual answered "yes" to any of the screening question(s), further investigations and/or assessment by a physician would often be prompted.

The existence of a medical advisory board was documented in most $(n=9)$ provinces and territories. These 


\begin{tabular}{|c|c|c|c|c|c|c|}
\hline Province or territory & $\begin{array}{l}\text { Mandatory } \\
\text { reporting }\end{array}$ & $\begin{array}{l}\text { Legal } \\
\text { immunity }\end{array}$ & $\begin{array}{l}\text { HE/CLD } \\
\text { reportable } \\
\text { conditions }\end{array}$ & $\begin{array}{l}\text { Use of health } \\
\text { questionnaire }\end{array}$ & MAB & Motor vehicle statute(s) \\
\hline British Columbia & Yes & Yes & None & Yes & Yes & $\begin{array}{l}\text { http://www.bclaws.ca/civix/document/id/ } \\
\text { complete/statreg/96318_00 }\end{array}$ \\
\hline Alberta & No & Yes & None & No & Yes & $\begin{array}{l}\text { http://www.qp.alberta.ca/documents/Acts/ } \\
\text { t06.pdf }\end{array}$ \\
\hline Saskatchewan & Yes & Yes & None & Yes & Yes & $\begin{array}{l}\text { http://www.qp.gov.sk.ca/documents/ } \\
\text { english/Statutes/Statutes/T18-1.pdf }\end{array}$ \\
\hline Manitoba & Yes & Yes & None & Yes & Yes & $\begin{array}{l}\text { http://web2.gov.mb.ca/laws/statutes/ccsm/ } \\
\text { pdf.php?cap=h60 }\end{array}$ \\
\hline Ontario & Yes & Yes & None & Yes & Yes & $\begin{array}{l}\text { https://www.ontario.ca/laws/ } \\
\text { statute/90h08\#BK304 }\end{array}$ \\
\hline Quebec & No & Yes & None & Yes & Yes & $\begin{array}{l}\text { http://legisquebec.gouv.qc.ca/en/ShowDoc/ } \\
\text { cs/C-24.2/ } \\
\text { http://legisquebec.gouv.qc.ca/en/pdf/ } \\
\text { cr/C-24.2,\%20R.\%2040.1.pdf }\end{array}$ \\
\hline Nova Scotia & No & Yes & None & Yes & Yes & $\begin{array}{l}\text { http://nslegislature.ca/legc/statutes/ } \\
\text { motor\%20vehicle.pdf }\end{array}$ \\
\hline $\begin{array}{l}\text { Newfoundland and } \\
\text { Labrador }\end{array}$ & Yes & Yes & None & Yes & Yes & $\begin{array}{l}\text { http://www.assembly.nl.ca/Legislation/sr/ } \\
\text { statutes/h03.htm }\end{array}$ \\
\hline Prince Edward Island & Yes & Yes & None & Yes & Yes & $\begin{array}{l}\text { https://www.princeedwardisland.ca/sites/ } \\
\text { default/files/legislation/h-05-highway_ } \\
\text { traffic_act.pdf }\end{array}$ \\
\hline New Brunswick & Yes & Yes & None & Yes & No & $\begin{array}{l}\text { http://laws.gnb.ca/en/showpdf/cs/M-17.pdf } \\
\text { http://laws.gnb.ca/en/showpdf/cr/83-42.pdf }\end{array}$ \\
\hline Nunavut & Yes & Yes & None & NR & NR & $\begin{array}{l}\text { http://www.gov.nu.ca/sites/default/files/ } \\
\text { motor_vehicles_act.pdf }\end{array}$ \\
\hline Northwest Territories & Yes & Yes & None & Yes & No & $\begin{array}{l}\text { https://www.justice.gov.nt.ca/en/files/ } \\
\text { legislation/motor-vehicles/ } \\
\text { motor-vehicles.a.pdf }\end{array}$ \\
\hline Yukon & Yes & Yes & None & Yes & No & $\begin{array}{l}\text { http://www.gov.yk.ca/legislation/acts/ } \\
\text { move_c.pdf }\end{array}$ \\
\hline
\end{tabular}

boards varied in composition across the country, with boards in some regions being composed solely of registered nurses and boards in others being composed of a combination of registered nurses and physicians. In regions with a medical advisory board, advice from the board was often sought for contested cases or when there was a lack of clarity in assessment of fitness to drive.

\section{Legal cases}

A search of WestlawNext Canada using the search strategy described in Appendix 1 identified 636 potential references, including 487 cases and decisions, 3 statutes and regulations, 6 entries in the Canadian Encyclopedic Digest, 10 legal memoranda, 12 insolvency court filings, 61 pleadings, motions, fact/briefs, 25 articles and newsletters and 32 texts and annotations. We found no civil or criminal cases involving either a physician caring for a patient with chronic liver disease involved in a motor vehicle collision or the patient himself or herself.

\section{Interpretation}

Our Canadian study found that most provinces and territories $(n=10)$ mandated physicians to report medical conditions that may impair a patient's ability to safely operate a motor vehicle. In all provinces and territories, reporting physicians were provided with legal immunity, which would be expected to lessen physicians' hesitancy to report unsafe drivers. However, chronic liver disease and associated hepatic encephalopathy are currently not explicitly listed as reportable medical conditions in any of the 13 Canadian provinces or territories.

Hepatic encephalopathy is encountered in patients with chronic liver disease and can have a wide range of clinical presentations. Strikingly, more than half of patients with chronic liver disease are estimated to have underlying minimal hepatic encephalopathy, a clinically challenging diagnosis that typically requires the use of specific psychometric tools. $^{22,23}$ Studies have highlighted substantial impairment in driving skills and an increased frequency of motor vehicle 
collisions and traffic violations among people with either minimal hepatic encephalopathy or overt hepatic encephalopathy. ${ }^{12,14}$ This underlines the need for both adequate diagnosis and counselling of patients with advanced liver disease regarding their fitness to drive. Interestingly, a 2015 international survey of experts in hepatic encephalopathy echoed this need: $99 \%$ of respondents agreed that minimal and overt hepatic encephalopathy affect driving skills. ${ }^{24}$ However, only $20 \%$ of these respondents assessed or made recommendations regarding patient safety and driving in their practices. This discrepancy was attributed to the fact that $75 \%$ of respondents found it difficult to deal with traffic safety laws, with only $50 \%$ indicating that they were aware of relevant local laws in their jurisdiction. ${ }^{24}$

The lack of understanding of local regulations and reporting requirements may deter physicians from engaging with patients with liver disease to adequately assess their fitness to drive. There is a need for easily accessible and concise resources that Canadian physicians can use to facilitate open conversations on this subject. The heterogeneity of motor vehicle rules and regulations across Canada further underlines this need. An evaluation of American regulations for hepatic encephalopathy and driving found that only $6 / 50$ $(12 \%)$ of states legally required physicians to report drivers who were medically impaired; no state explicitly identified chronic liver disease and/or hepatic encephalopathy as reportable conditions. Surprisingly, only $38 \%$ of states with mandatory reporting requirements provided legal immunity to physicians, which may dissuade physicians from reporting medically unfit drivers. ${ }^{16}$

In Canada, the statutes in most provinces and territories do not cover specific diseases, leaving the specifics to be determined by orders in council, as for example in Ontario. ${ }^{25}$ This approach is probably a reflection of the wide variety of medical conditions that can affect driving ability. A tool commonly used by provinces and territories is the Canadian Council of Motor Transport Administrators' Medical Standards for Drivers. This tool was created by representatives from each jurisdiction to help standardize the assessment of driver fitness nationally for both commercial and noncommercial drivers. A number of disease states are discussed, including diabetes, psychiatric disorders, coronary disease and seizures. Chronic liver disease, however, is not explicitly addressed in this tool. Although there are recommendations in the tool regarding driving safety and dementia, in our opinion hepatic encephalopathy does not fit well into these recommendations. Hepatic encephalopathy often fluctuates in character, like delirium, which is considered a transient impairment for driving purposes. Furthermore, unlike the situation for dementia, drugs including lactulose and rifaximin can substantially improve hepatic encephalopathy. ${ }^{26-31}$ However, it is important to note that the effects of these therapies on driving performance and overall safety are not well studied. It is also unclear whether maintaining long-term therapy will have a positive impact on the safe operation of motor vehicles; an outcome that would affect the development of policies pertaining to hepatic encephalopathy and fitness to drive.
We were not able to identify any legal cases in Canada to date regarding driving with hepatic encephalopathy. In the US, a similar lack of cases was previously noted. ${ }^{16}$ The lack of cases in Canada is consistent with the fact that this country is less litigious from a medicolegal standpoint than the US. It is difficult to say exactly why no cases have occurred, but it may be because hepatic encephalopathy is not as well recognized or as easily recognized as conditions such as seizures, stroke and other cardiovascular disease.

\section{Limitations}

There are several practical limitations to our study. The provincial and territorial regulations may not reflect how clinicians in Canada practise at the local level. As such, our study could not evaluate the specific variables or barriers faced by physicians caring for patients with hepatic encephalopathy. We recognize that one of these barriers may be the difficulty in identifying patients with minimal hepatic encephalopathy. The current gold standard for diagnosing minimal hepatic encephalopathy is the Psychometric Hepatic Encephalopathy Score (PHES), a paper-based test assessing attention, visuospatial perception and construction, psychomotor speed and motor accuracy. ${ }^{22,32,33}$ Other diagnostic tools for minimal hepatic encephalopathy include electroencephalography, the critical flicker test, continuous reaction time and a smartphone/tablet app called EncephalApp (Stroop App). ${ }^{34-37}$ The use of these tools in a clinical setting may be limited by various factors including availability, cost, timing and the health care provider's competence in administering the tests. An anonymous survey would be useful to improve our understanding of the factors that impede the identification, counselling and reporting of unfit drivers at the local level. Another possible limitation is that our study was focused on jurisdictional statutes and we assumed that the Canadian Council of Motor Transport Administrators' Medical Standards for Drivers is the main regulatory guidance in Canada that supplements the statutes. We may have missed specific regulations or orders in council that may provide increased detail. Finally, although WestlawNext Canada is the most comprehensive legal database, it is not $100 \%$ complete so there is the possibility that a decision was missed.

\section{Conclusion}

Patients with chronic liver disease with hepatic encephalopathy (either minimal or overt) are involved in more motor vehicle collisions than those without hepatic encephalopathy. Overt hepatic encephalopathy in the context of chronic liver disease is readily identified clinically and is not currently a reportable medical condition as it pertains to operating a vehicle safely. This highlights the need to increase overall awareness of the impact of hepatic encephalopathy (especially minimal hepatic encephalopathy, which is typically underdiagnosed) on driving safety in the public and among health care providers. Our future directions include evaluating at the clinician-patient level the specific barriers and variables encountered by physicians in identifying and reporting patients with encephalopathy who are unfit to 
drive. It would be useful to exapand the study to evaluate other national jurisdictions for cases involving patients with hepatic encephalopathy and the physicians who fail to report them. A better understanding of how other nations deal with this issue could help to inform policy development in Canada.

\section{References}

1. Scaglione S, Kliethermes S, Cao G, et al. The epidemiology of cirrhosis in the United States: a population-based study. 7 Clin Gastroenterol 2015;49:690-6.

2. Myers RP, Krajden M, Bilodeau M, et al. Burden of disease and cost of chronic hepatitis C infection in Canada. Can 7 Gastroenterol Hepatol 2014; 28:243-50.

3. Vernon G, Baranova A, Younossi ZM. Systematic review: the epidemiology and natural history of non-alcoholic fatty liver disease and non-alcoholic steatohepatitis in adults. Aliment Pharmacol Ther 2011;34:274-85.

4. Leise MD, Poterucha JJ, Kamath PS, et al. Management of hepatic encephalopathy in the hospital. Mayo Clin Proc 2014;89:241-53.

5. Vilstrup H, Amodio P, Bajaj J, et al. Hepatic encephalopathy in chronic liver disease: 2014 practice guideline by the American Association for the Study of Liver Diseases and the European Association for the Study of the Liver. Hepatology 2014;60:715-35.

6. Sharma P, Sharma BC, Puri V, et al. Critical flicker frequency: diagnostic tool for minimal hepatic encephalopathy. 7 Hepatol 2007;47:67-73.

7. Romero-Gómez M, Boza F, García-Valdecasas MS, et al. Subclinical hepatic encephalopathy predicts the development of overt hepatic encephalopathy. Am 7 Gastroenterol 2001;96:2718-23.

8. Shaw J, Bajaj JS. Covert hepatic encephalopathy: Can my patient drive? 7 Clin Gastroenterol 2017;51:118-26.

9. Amodio P, Montagnese S, Gatta A, et al. Characteristics of minimal hepatic encephalopathy. Metab Brain Dis 2004;19:253-67.

10. Das A, Dhiman RK, Saraswat VA, et al. Prevalence and natural history of subclinical hepatic encephalopathy in cirrhosis. 7 Gastroenterol Hepatol 2001;16:531-5.

11. Wein C, Koch H, Popp B, et al. Minimal hepatic encephalopathy impairs fitness to drive. Hepatology 2004;39:739-45.

12. Kircheis G, Knoche A, Hilger N, , et al. Hepatic encephalopathy and fitness to drive. Gastroenterology. 2009 Nov; 137(5):1706-1715.e1-9.

13. Watanabe A, Tuchida T, Yata Y, et al. Evaluation of neuropsychological function in patients with liver cirrhosis with special reference to their driving ability. Metab Brain Dis 1995;10:239-48.

14. Bajaj JS, Saeian K, Schubert CM, et al. Minimal hepatic encephalopathy is associated with motor vehicle crashes: the reality beyond the driving test. Hepatology 2009;50:1175-83.

15. Canadian Council of Motor Transport Administrators. Canadian motor vehicle traffic collision statistics: 2015. Ottawa: Transport Canada; 2017:6.

16. Cohen SM, Kim A, Metropulos M, et al. Legal ramifications for physicians of patients who drive with hepatic encephalopathy. Clin Gastroenterol Hepatol 2011;9:156-60.

17. Confidentiality: patients' fitness to drive and reporting concerns to the DVLA or DVA. London (UK): General Medical Council; 2017:3. Available: www. gmc-uk.org/guidance (accessed 2018 July 27).

18. Sokol D. Should healthcare professionals breach confidentiality when a patient is unfit to drive? BM7 2017;356:j1505.

19. Canadian Medical Association. CMA driver's guide: determining medical fitness to operate motor vehicles. 9th ed. Ottawa: Joule; 2017:188.

20. Determining driver fitness in Canada. 13th ed. Ottawa: Canadian Council of Motor Transport Administrators; 2013.

21. What's In LawSource I Westlaw Canada [Internet]. Available: https://www. westlawnextcanada.com/whats-in-lawsource/ (accessed 2018 Sept. 26).
22. Weissenborn K. Diagnosis of minimal hepatic encephalopathy. 7 Clin Exp Hepatol 2015;5(Suppl 1):S54-9.

23. Stinton LM, Jayakumar S. Minimal hepatic encephalopathy. Can 7 Gastroenterol 2013;27:572-4

24. Lauridsen MM, Bajaj JS. Hepatic encephalopathy treatment and its effect on driving abilities: a continental divide. 7 Hepatol 2015;63:287-8.

25. Report a medically unfit driver: physicians. Toronto: Ontario Ministry of Transportation; [modified 2018]. Available: http://www.mto.gov.on.ca/english/ safety/medically-unfit-driver-physicians.shtml (accessed 2018 July 19).

26. Gupta D, Ingle M, Shah K, et al. Prospective comparative study of inhibitory control test and psychometric hepatic encephalopathy score for diagnosis and prognosis of minimal hepatic encephalopathy in cirrhotic patients in the Indian subcontinent. 7 Dig Dis 2015;16:400-7.

27. Prasad S, Dhiman RK, Duseja A, et al. Lactulose improves cognitive functions and health-related quality of life in patients with cirrhosis who have minimal hepatic encephalopathy. Hepatology 2007;45:549-59.

28. Sharma P, Sharma BC, Puri V, et al. An open-label randomized controlled trial of lactulose and probiotics in the treatment of minimal hepatic encephalopathy. Eur 7 Gastroenterol Hepatol 2008;20:506-11.

29. Shukla S, Shukla A, Mehboob S, et al. Meta-analysis: the effects of gut flora modulation using prebiotics, probiotics and synbiotics on minimal hepatic encephalopathy. Aliment Pharmacol Ther 2011;33:662-71.

30. Bass NM, Mullen KD, Sanyal A, et al. Rifaximin treatment in hepatic encephalopathy. N Engl 7 Med 2010;362:1071-81.

31. Sharma BC, Sharma P, Lunia MK, et al. A randomized, double-blind, controlled trial comparing rifaximin plus lactulose with lactulose alone in treatment of overt hepatic encephalopathy. Am 7 Gastroenterol 2013;108:1458-63.

32. Montagnese S, Biancardi A, Schiff S, et al. Different biochemical correlates for different neuropsychiatric abnormalities in patients with cirrhosis. Hepatology 2011;53:558-66.

33. Nabi E, Bajaj JS. Useful tests for hepatic encephalopathy in clinical practice. Curr Gastroenterol Rep 2014;16:362.

34. Parsons-Smith BG, Summerskill WH, Dawson AM, et al. The electroencephalograph in liver disease. Lancet 1957;273:867-71.

35. Kircheis G, Wettstein M, Timmermann L, et al. Critical flicker frequency for quantification of low-grade hepatic encephalopathy. Hepatology 2002; 35:357-66.

36. Elsass P, Christensen SE, Jørgensen F, et al. Number connection test and continuous reaction times in assessment of organic and metabolic encephalopathy: a comparative study. Acta Pharmacol Toxicol (Copenh) 1984;54:115-9.

37. Bajaj JS, Heuman DM, Sterling RK, et al. Validation of EncephalApp, smartphone-based stroop test, for the diagnosis of covert hepatic encephalopathy. Clin Gastroenterol Hepatol 2015;13:1828-35.e1.

Affiliations: University of Calgary Liver Unit, Department of Medicine (Nguyen, Swain, Congly), Division of Gastroenterology and Hepatology, Calgary, Alta.; McGill University Health Centre (Wong), Royal Victoria Hospital, Montréal, Que.

Contributors: Stephen Congly conceived and designed the study. Henry Nguyen and Stephen Congly contributed to data acquisition. All of the authors contributed to data analysis. Henry Nguyen drafted the manuscript and all of the authors revised it critically for important intellectual content. All of the authors gave final approval of the version to be published and agreed to be accountable for all aspects of the work.

Acknowledgement: The authors would like to thank Karen Olympia-Sy for her help in reviewing the legal search strategy for this study.

Supplemental information: For reviewer comments and the original submission of this manuscript, please see www.cmajopen.ca/content/6/4/ E575/suppl/DC1. 